University of Nebraska - Lincoln

DigitalCommons@University of Nebraska - Lincoln

USDA National Wildlife Research Center - Staff Publications
U.S. Department of Agriculture: Animal and Plant Health Inspection Service

2013

\title{
Changes in grouping patterns of saiga antelope in relation to intrinsic and environmental factors in Mongolia
}

B. B. Buuveibaatar

University of Massachusetts, bbayarba@eco.umass.edu

T. K. Fuller

University of Massachusetts

A. E. Fine

Wildlife Conservation Society

B. Chimeddorj

World Wide Fund for Nature

J. K. Young

Utah State University, julie.k.young@aphis.usda.gov

See next page for additional authors

Follow this and additional works at: https://digitalcommons.unl.edu/icwdm_usdanwrc

Buuveibaatar, B. B.; Fuller, T. K.; Fine, A. E.; Chimeddorj, B.; Young, J. K.; and Berger, J., "Changes in grouping patterns of saiga antelope in relation to intrinsic and environmental factors in Mongolia" (2013). USDA National Wildlife Research Center - Staff Publications. 1237.

https://digitalcommons.unl.edu/icwdm_usdanwrc/1237

This Article is brought to you for free and open access by the U.S. Department of Agriculture: Animal and Plant Health Inspection Service at DigitalCommons@University of Nebraska - Lincoln. It has been accepted for inclusion in USDA National Wildlife Research Center - Staff Publications by an authorized administrator of DigitalCommons@University of Nebraska - Lincoln. 


\section{Authors}

B. B. Buuveibaatar, T. K. Fuller, A. E. Fine, B. Chimeddorj, J. K. Young, and J. Berger 


\title{
Changes in grouping patterns of saiga antelope in relation to intrinsic and environmental factors in Mongolia
}

\author{
B. Buuveibaatar ${ }^{1,2}$, T. K. Fuller ${ }^{1}$, A. E. Fine ${ }^{2}$, B. Chimeddorj ${ }^{3}$, J. K. Young ${ }^{4}$ \& J. Berger ${ }^{5,6}$ \\ 1 Department of Environmental Conservation, University of Massachusetts, Amherst, MA, USA \\ 2 Mongolia Program, Wildlife Conservation Society, Ulaanbaatar, Mongolia \\ 3 Mongolia Program Office, World Wide Fund for Nature, Ulaanbaatar, Mongolia \\ 4 USDA-WS-National Wildlife Research Center and the Department of Wildland Resources, Utah State University, Logan, UT, USA \\ 5 Organismal Biology and Ecology, University of Montana, Missoula, MT, USA \\ 6 Wildlife Conservation Society, New York, NY, USA
}

\section{Keywords}

Saiga tatarica mongolica; social structure; season; group size; Mongolia.

\section{Correspondence}

Bayarbaatar Buuveibaatar, Department of Environmental Conservation, University of Massachusetts, 160 Holdsworth Way,

Amherst, MA 01003, USA

Email: bbayarba@eco.umass.edu

Editor: Andrew Kitchener

Received 24 December 2012; revised 26 March 2013; accepted 5 April 2013

doi:10.1111/jzo.12045

\begin{abstract}
Factors that affect group sizes in large ungulates are generally poorly understood for species from remote regions. Understanding grouping patterns is important for effective species management, but is lacking for the endangered Mongolian saiga (Saiga tatarica mongolica). We studied seasonal changes in the group size and social structure of saigas in relation to environmental and anthropogenic factors in western Mongolia during 2009-2012. To identify group size and composition, we observed saigas monthly while conducting monitoring surveys, and weekly while tracking radio-collared animals. We observed 9268 individuals; median group size was $6.5(\mathrm{SE}=1.7$; range $=1-121)$, and groups of $1-5$ animals were most common. Seasonality exerted strong effects with the smallest groups in June and largest in December. The largest mixed and nursery groups formed during pre-rutting and summer seasons, respectively, but no seasonal differences were detected for bachelor groups. The best fitting model, including Normalized Difference Vegetation Index, predation rate and season as covariates, explained $\sim 76 \%$ of the variation in monthly 'typical' group size. Our results are concordant with studies of other arid-adapted ungulates and suggest vegetation productivity, predation rate and biological cycles are responsible for saiga grouping patterns in Mongolia.
\end{abstract}

\section{Introduction}

Several factors influence grouping patterns of ungulates and other social mammals. Grouping is a common response to predation, with a primary benefit of reduced risk of an individual being preyed upon, through increased vigilance (Berger, 1978; Roberts, 1996; Li et al., 2012). Social structure in ungulates is closely related to ecological factors such as habitat type and food availability (Jarman, 1974; Thirgood, 1996). Group size tends to increase with population density (Coulson, 1993; Borkowski, 2000), but habitat openness may also affect grouping patterns (Estes, 1974; Jarman, 1974). Further, grouping behavior is risk sensitive and group size is positively associated with both predation risk and vegetation productivity (Berger, 1988; Banks, 2001).

Understanding the interaction between social systems and life-history patterns is an essential prerequisite for effective conservation (Festa-Bianchet \& Apollonio, 2003); it is the foundation upon which monitoring schemes, population models and management strategies are built. Because populations of large mammals are strongly structured (Gaillard, Festa-Bianchet \& Yoccoz, 1998), additional demographic indicators, such as sex ratios, group composition and recruitment rates, are often used to monitor populations (Ginsberg \& Milner-Gulland, 1994; Milner-Gulland et al., 2003; Buuveibaatar, 2011).

The saiga antelope (Saiga tatarica) is a migratory herding species of semi-arid ecosystems of Central Asia (Bekenov, Grachev \& Milner-Gulland, 1998). Two subspecies exist, the nominate form (S.t.tatarica) in Russia, Kazakhstan and Uzbekistan, and the Mongolian saiga (S.t. mongolica; Kholodova et al., 2006). The Mongolian saiga occurs in four subpopulations (Amgalan, Buuveibaatar \& Chimeddorj, 2008) in semi-desert or dry steppe depressions in western Mongolia (Bannikov, 1954). While the nominate subspecies undertakes large scale migration tracking greenness of vegetation (Bekenov, Grachev \& Milner-Gulland, 1998; Singh et al., 2010), the Mongolian subspecies does not show nomadic behavior with pronounced seasonal movements (Bannikov, 1954). Saigas are categorized as critically endangered globally (IUCN, 2011); however, Mongolian saigas have been assessed as endangered (Clark \& Javzansuren, 2006). The Mongolian saiga population appears stable in total size, probably owing to enhanced protection (Chimeddorj, 
Amgalan \& Buuveibaatar, 2009), and estimates suggest a population of 5000-7000 (Lushchekina et al., 1999; Young et al., 2010). While many aspects of saiga ecology in Mongolia, such as habitat requirements and neonate survival, are relatively well understood (Berger et al., 2008; Buuveibaatar et al., 2013), little is known about variation in grouping patterns and how environmental and human factors may affect them. Monitoring programmes on Mongolian saigas began in the late 1990s, but efforts were largely confined to winter (Chimeddorj et al., 2009). There is a need for a year-round assessment of grouping patterns to better inform saiga conservation actions, especially because anthropogenic threats are increasing (Lkhagvasuren, Chimeddorj \& Sanjmyatav, 2012).

Here, we report seasonal changes in group size and composition of saiga in relation to biotic and abiotic factors. Our primary objectives were to determine (1) the extent to which group sizes differed between seasons, and (2) the relative importance of factors contributing to monthly variation in grouping patterns. The logical bases for our expectations are as follows. We expected grouping patterns of saigas to be positively correlated with vegetation productivity [indexed as Normalized Difference Vegetation Index (NDVI); Bon et al., 1990]. Also, animals in larger groups benefit from the dilution effect, as the individual predation risk per attack is reduced as a function of group size (Hamilton, 1971). Thus, we expected saiga group size would increase during periods when the predation rate is high. We also expected group size to be negatively influenced by the population density of livestock; livestock probably displace saiga into marginal habitat, resulting in larger groups using these areas. Finally, we expected saiga group size to vary in accordance with seasonality and life history traits, such as calving, rutting and migration.

\section{Material and methods}

\section{Study area}

Our research was conducted in western Mongolia across the entire range of Mongolian saigas; we excluded the tiny Mankhan subpopulation as it has only 20-30 animals. Our dataset covered three main subpopulations of saigas: Shargiin Gobi, Khuisiin Gobi and Dorgon Plain (Fig. 1). The main human populations in the area are concentrated in soums (villages/towns) and saiga range encompasses eight soum territories in the Khovd (Darvi and Chandmani soums) and Gobi-Altai Aimags (Fig. 1). Semi-nomadic herders are at their highest density during autumn within the study area (Buuveibaatar, Young \& Fine, 2010). Domestic livestock consists primarily of goats and sheep with small numbers of camels and horses. There is a lack of permanent surface water and local herders rely heavily on hand-drawn wells or snow.

The study area is bounded by the Altay Mountains to the west; elevations range from 900 to $4070 \mathrm{~m}$. The region is desert-like with a short growing season, long harsh winters and a strongly variable climate, which governs the availability of food plants (Yu et al., 2004). During 1975-2007, average air temperature during summer and winter was 18 and $-20^{\circ} \mathrm{C}$, respectively (Buuveibaatar et al., 2013). The study area receives $\sim 100 \mathrm{~mm}$ precipitation annually. Vegetation is sparse and onions (Allium spp.), grasses (Stipa spp.) and anabasis (Anabasis brevifolia) are the most common plants

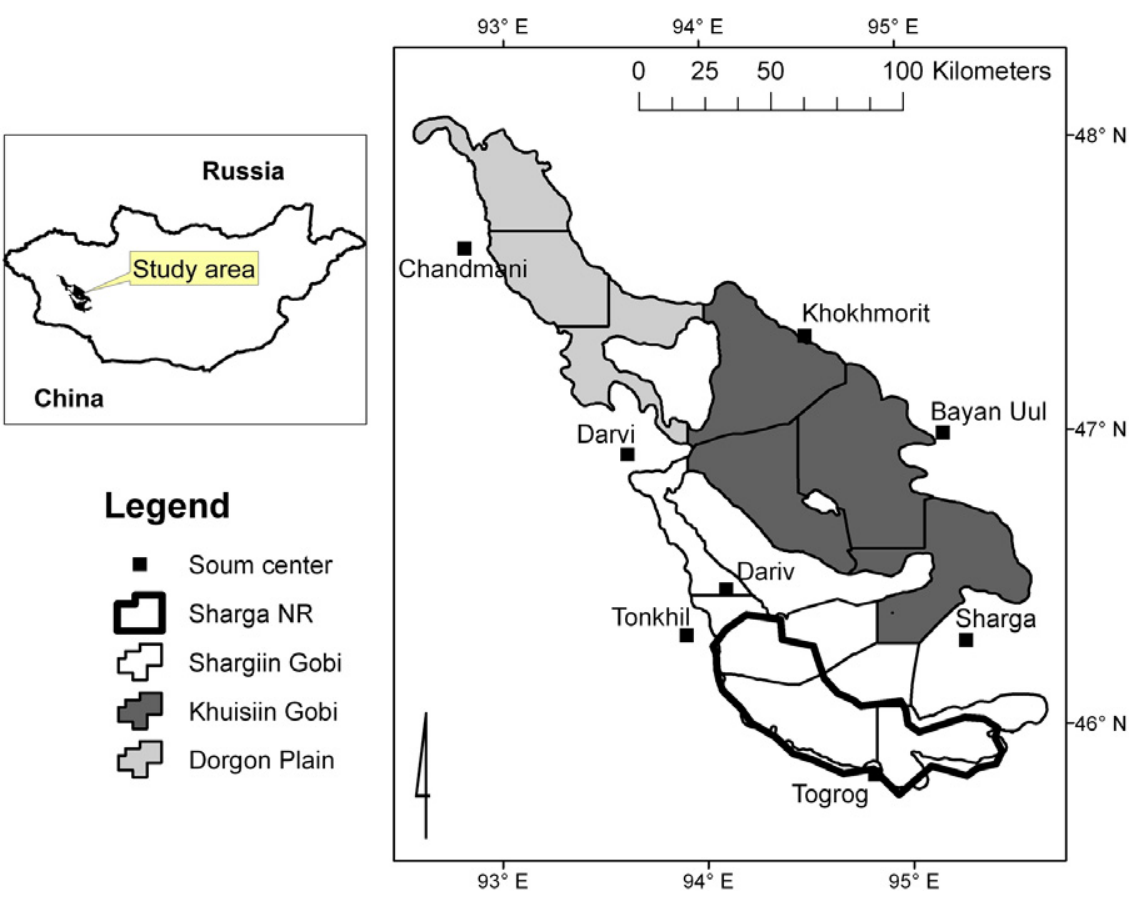

Figure 1 A map of the study area in western Mongolia. Monitoring and patrolling areas of 11 saiga rangers are shown as polygons. 
(Buuveibaatar, Gunbat \& Fuller, 2012). Common predators in this system are grey wolves (Canis lupus), red foxes (Vulpes vulpes), corsac foxes ( V. corsac), lynx (Lynx lynx) and raptors, such as golden eagles (Aquila chrysaetos) and cinereous vultures (Aegypius monachus).

\section{Data sources}

Two data sources for saiga groups were analyzed. First, we used saiga rangers' monthly monitoring data collected during November 2009 to December 2011. As a part of the 'Saiga Conservation Project' implemented by World Wide Fund for Nature (WWF), a total of 11 saiga rangers (three in Dorgon Plain, four in Shargiin Gobi and four in Khuisiin Gobi) conducted monthly observations of saiga groups (Fig. 1). All rangers received training on monitoring of saigas and were equipped with binoculars, GPS units, compasses, maps and rangefinders. Monitoring occurred at the same time in each month to avoid double observation of saiga groups by different saiga rangers. During the monthly monitoring, each ranger recorded group size and composition along a prioridefined fixed transects. A saiga group was defined as one or more saigas at least $500 \mathrm{~m}$ from other conspecifics that moved cohesively. The WWF protocol did not include a method to obtain observer error, so for this study, we assume it to be constant across rangers, days, seasons and years. Second, 116 saiga calves were captured and fitted with a 70-g expandable VHF radio-collar to monitor their movements and survival during 2008-2010 (Buuveibaatar et al., 2013). Animalhandling methods were approved by the Institutional Animal Care and Use Committee at the University of Massachusetts Amherst (protocol 2010-0001). Up to three times per week, we located and recorded group size and composition of groups of saigas encountered while radio-tracking collared individuals. For the monitoring data of the marked animals, we assumed all observations to be independent because no more than one observation was made for each group on any given day. Weekly observations of saiga group size were pooled into months to determine average monthly group size.

\section{Group size definitions}

We describe the distribution of group sizes using median values for comparison with other studies, and because group sizes, in general, typically exhibit an aggregated (right-skewed) distribution (where most groups are small, few are large and a very few are very large), and thus are not normally distributed or accurately described by mean values. For modeling purposes, we calculated and used 'typical group size' to examine how saiga grouping patterns respond to environmental and social factors. Typical group size is defined as $\Sigma G i^{2} / \Sigma G i$, where $G i$ is the size of the $i$ th group (Jarman, 1974); this identifies the group size in which the most animal lives (also 'mean crowding'; Reiczigel et al., 2008). Typical group size has advantages over mean or median group size because it is less sensitive to the number of records of solitary animals (White et al., 2012).

\section{Predictor variables}

We evaluated vegetation productivity, predation rate, mean temperature and precipitation, distribution and number of livestock herders, and a dummy predictor variable.

1 To estimate vegetation productivity in saiga range, we acquired NDVI scenes from the 10-day SPOT (Satellite Pour l' Observation de la Terre $)$ dataset $(1 \times 1 \mathrm{~km}$ spatial resolution - http://www.spotimage.fr), corresponding to the study period during November 2009-March 2012 (i.e. 31 months $\times 3=93$ scenes). To estimate monthly variation in NDVI value, random points $(n=10000)$ were generated within the entire saiga range, using the Hawth's Tools extension of ArcGIS 9.3 (ESRI), of which 9257 were left after removing the points from water bodies and high altitudes, where saigas were unlikely to occur. The NDVI values were extracted for all randomly generated points using the Extraction tool in the Spatial Analyst extension. Ten-day NDVI values for each random point were pooled by month to estimate average monthly NDVI values for all years.

2 A predation rate index was developed using survival data from the radio-collared saiga calves during 2008-2010 (Buuveibaatar et al., 2013). During the 3-year survey, 56 $(48 \%)$ of the marked animals died from five sources of mortality, including raptors $(36 \%)$, foxes $(18 \%)$, lynx $(2 \%)$, parasites $(2 \%)$ and unknown causes $(43 \%)$. To calculate predation rate, we estimated monthly mortality rates for each cohort by determining the proportion of the marked animals killed by predators (e.g. raptors, foxes and lynx) and averaged these estimates across years. Predation rate on calves was highest in July (e.g. $\sim 30 \%$ of marked animals killed by predators during 2008-2010; Buuveibaatar et al., 2013).

3 Mean temperature and total precipitation were calculated for each month; data were derived from local meteorological stations in the eight soums adjacent to saiga range (Fig. 1).

4 Data on seasonal distribution and number of nomadic livestock herders in the study area throughout the year were obtained from WWF Mongolia databases. Because livestock data were incomplete for each herder, we used density of livestock herders as a proxy for livestock population density. The density of livestock herders was calculated by dividing the total number of herders by the size of the study area for four seasons: winter (December-February), spring (MarchMay), summer (June-September) and autumn (OctoberNovember). Seasons were based on movements of the livestock herders within the study area as determined from our own observations and from interviews with rangers monitoring livestock herder activity.

5 Finally, to account for variation in group size in relation to seasonal sociality (e.g. calving, rutting and migration), we created a dummy variable using seven biological seasons: calving (June), summer (July-August), autumn (September-October), pre-rutting (November-December), rutting (January), winter (February-March) and spring (April-May), based on behavioral and climatic considerations (Buuveibaatar, 2011). 
Table 1 Descriptive statistics of median size of group types (pooled across months and years), based on observations during VHF tracking and monthly population monitoring. Median group sizes were compared using nonparametric Kruskal-Wallis tests

\begin{tabular}{|c|c|c|c|c|c|c|c|c|}
\hline \multirow[b]{2}{*}{ Group type } & \multicolumn{3}{|l|}{ Tracking } & \multicolumn{3}{|l|}{ Monitoring } & \multicolumn{2}{|c|}{ Difference } \\
\hline & Median \pm SE & Range & $n$ & Median \pm SE & Range & $n$ & $\bar{H}$ & $P$ \\
\hline Mixed & $9.5 \pm 1.4$ & $2-39$ & 110 & $11.0 \pm 1.7$ & $2-56$ & 195 & 1.92 & 0.19 \\
\hline Nursing & $7.0 \pm 1.1$ & $2-35$ & 157 & $5.5 \pm 0.8$ & $2-21$ & 84 & 2.07 & 0.06 \\
\hline Bachelor & $4.0 \pm 0.5$ & $1-8$ & 18 & $4.5 \pm 0.7$ & $1-13$ & 55 & 1.04 & 0.55 \\
\hline
\end{tabular}

\section{Data analysis}

To examine variation in social structure, groups were defined as bachelor groups (males), nursery groups (females and subadults or juveniles of unknown sex) and mixed-sex groups. Cases, in which sex or group composition could not be determined reliably, were excluded from the analysis. There were no differences in median group sizes between the monitoring and tracking data for all types of groups (Table 1). Therefore, we combined both datasets for analysis. Group compositions were identified for $619(\sim 74 \%)$ of the groups across years, and included 197 mixed, 324 nursing and 98 bachelor herds (Table 1). Monthly observations were pooled into the seven biological seasons. A Kruskal-Wallis one-way analysis of variance (ANOVA) was used to test for differences in monthly group size and seasonal group composition of saigas. Differences in monthly median and typical group sizes were examined using Mann-Whitney tests. Median and typical group sizes are reported with standard errors (SE).

Generalized linear models (GLM) with Gaussian error structure were used to evaluate effects of NDVI, predation rate, climate, density of livestock herders and seasonality on monthly variation in typical group size of saiga. We excluded monthly total precipitation $\left(r^{2}=76.4, F=32.5, P<0.001\right)$ and average temperature $\left(r^{2}=90.1, F=90.8, P<0.001\right)$ because they were positively related to average monthly NDVI value. Therefore, our final model included four explanatory variables (NDVI, predation rate, livestock herder density and season). All variables were assessed for correlation, using variance inflation factors (VIF), which show how much the variance of the coefficient estimate is being inflated by multicollinearity; a value exceeding five is considered as evidence of multi-collinearity (Das \& Chatterjee, 2011). None of the variables considered showed a high VIF $(\mathrm{NDVI}=1.61$; predation rate $=1.98$; herder density $=1.32$; and season $=1.31$ ); hence, they were included in the same model. We used the Akaike Information Criterion, corrected for small sample sizes (AICc) and Akaike weights for model selection (Burnham \& Anderson, 2002). We considered the model with the smallest AICc value to be the best model to fit the data and any model within 2 AICc values as a competing model (Burnham \& Anderson, 2002). Akaike weights were used to assess the strength of evidence of one model versus another. Relative importance of variables affecting saiga group size was evaluated using the method of hierarchical variance partitioning (Walsh \& MacNally, 2004). All the statistical analyses were done in program R 2.15.2 (R Development Core Team, 2008).

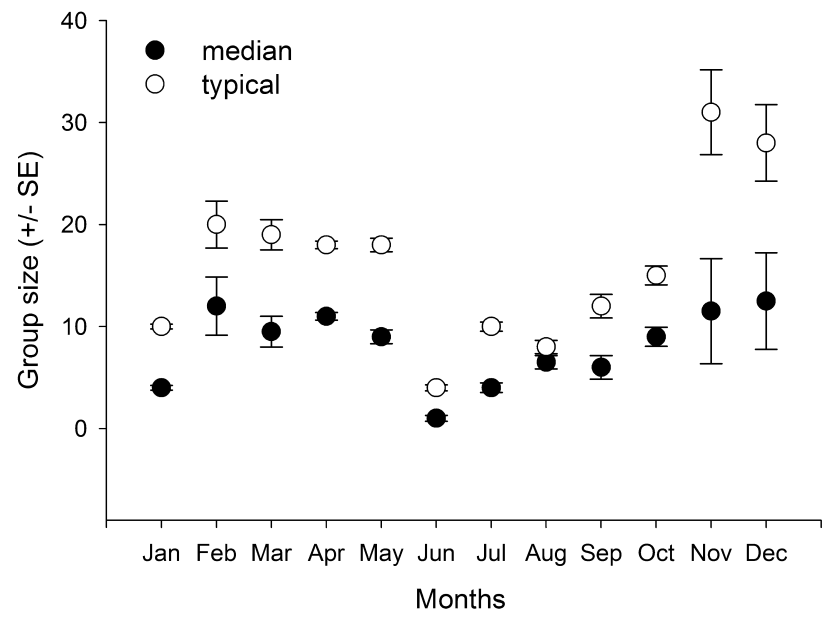

Figure 2 Monthly variation in typical and median group size of Mongolia saiga (Saiga tatarica mongolica) during 2009-2012 in western Mongolia.

\section{Results}

In total, 836 groups and 9268 individuals were observed between November 2009 and March 2012. Groups of 1-5 animals were the most $(36.6 \%)$ frequent, followed by $6-10$ individuals $(26.4 \%)$ and $11-15$ individuals (13.2\%); groups with $>30$ individuals were rare (e.g. $5.5 \%$ of the total). Overall median group size was $8.0 \pm 1.7$ (range, $1-121$ individuals). Median group sizes varied monthly (Kruskall-Wallis one-way ANOVA: $\left.H_{11}=103.35, P<0.001\right)$ with smallest groups forming in June $(1.5 \pm 0.3)$ and largest in December (12.5 \pm 1.7; Fig. 2). Similarly, typical group size was smallest in June (3.0 \pm 0.4$)$ and largest in November (31.0 \pm 1.8; Fig. 2). Typical group sizes varied monthly (Kruskall-Wallis one-way ANOVA: $H 11=115.57, P<0.001)$. Overall typical group size $(16.0 \pm 2.3)$ was twice larger than median group size (Fig. 2; Mann-Whitney test: $\left.W_{l}=194.5, P<0.01\right)$.

Median size of mixed groups was largest during the prerutting period (14.5 \pm 1.6$)$ and smallest during calving $(7.5 \pm$ 1.5; Fig. 3), and varied between seasons (Kruskall-Wallis oneway ANOVA: $\left.H_{6}=14.17, P<0.01\right)$. For nursery groups, median group size was the lowest during calving season $(1.5 \pm$ $0.1)$ and largest during summer $(6.5 \pm 1.2$; Kruskall-Wallis one-way ANOVA: $\left.H_{6}=9.34, P=0.05\right)$. Median bachelor group size ranged from 2.0 to 5.0 males ( $\mathrm{SE}=0.2$ to 1.2 ) and median group size did not differ seasonally (Kruskall-Wallis one-way ANOVA: $H_{6}=1.21, P=0.26$ ). 


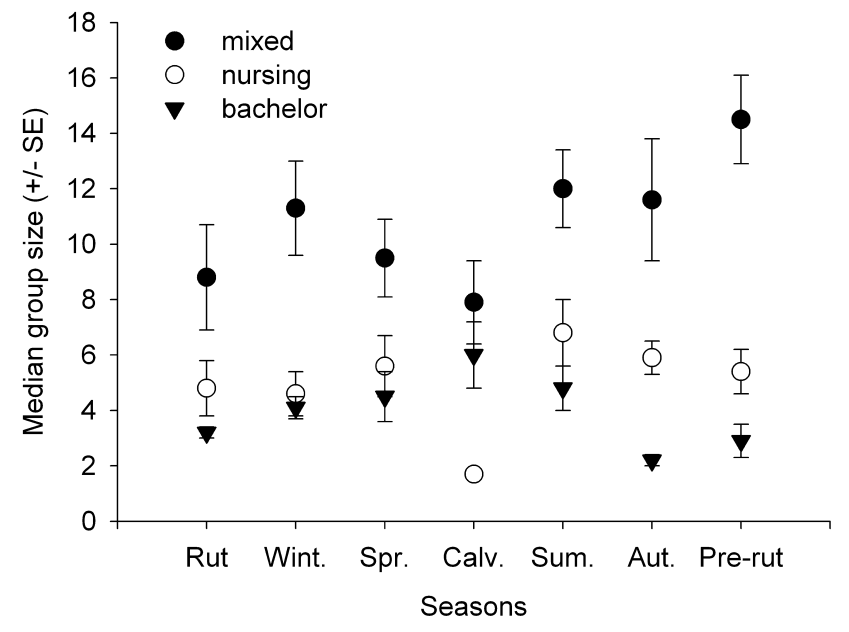

Figure 3 Seasonal changes in group composition of Mongolian saiga (Saiga tatarica mongolica) during 2009-2012 in western Mongolia.

The best model determined by GLM, including the factors NDVI, predation rate and season, explained $\sim 76 \%$ of the variation in typical monthly group size of saigas (Table 2). This model accounted for $56 \%$ of the AICc weights among the 14 subset models we considered. The exclusion of predation rate from the best model produced the second-ranked model, which was competitive (AICc weight $=24 \%$; Table 2). Relative support of NDVI $(39 \%)$ was the greatest, followed by predation rate $(34 \%)$, season $(22 \%)$, and herder density $(5 \%)$, in explaining changes in typical group size. In the top model, typical group size was negatively related to NDVI and predation rate, and season was positively associated with monthly variation (Table 3 ).

\section{Discussion}

Although the range of saiga group size in this study was large (range $=1-121$ ), the distribution was heavily skewed towards smaller groups. Groups of 1-5 animals were encountered most frequently $(36.6 \%)$. Small groups are more common in arid environments, where food is likely to be sparsely distributed (Berger, 1988). Goitered gazelles (Gazella subgutturosa) also occupy areas of Mongolia where high-quality food items are sparse, and individuals tend to be dispersed in relatively small herds (Blank et al., 2012).

Changes in monthly group size appeared to be dependent on the annual biological cycle of saigas. This was expected since many large and medium-sized ungulates congregate during the rut and then form smaller groups at other times (Borkowski \& Furubayashi, 1998; Blank et al., 2012). The median mixed-group size of saigas was lowest during summer, similar to populations in Kazakhstan and Russia (Bekenov et al., 1998; Kuhl, 2008). Grouping in smaller herds in summer is probably associated with calving. Pregnant females leave their groups and remain solitary during this period (Sokolov, 1974). Saiga groups reached maximum size during the pre- rutting season (e.g. November-December), with a secondary peak in group size observed in February. These observations probably reflect saiga reproductive behavior. Males start establishing harems at the beginning of the rut (Dulamceren \& Amgalan, 1994), and harem herds join together to form larger groups once the rut ends (Bekenov et al., 1998).

Food ultimately limits the formation of groups in many ungulates across different landscapes (e.g. bighorn sheep Ovis canadensis: Payer \& Coblentz, 1997; sika deer Cervus nippon: Borkowski \& Furubayashi, 1998). However, contrary to our prediction, we found a negative association between group size and NDVI. In other words, large groups were more common when food availability was lowest during winter and spring (November-April). Food availability is limited by snow cover during winter and saigas may be forced to concentrate in small patches of good vegetation, resulting in formation of larger groups. Similarly, a mega-herd of Mongolian gazelles was observed in eastern Mongolia, when availability of suitable foraging patches was severely reduced by severe drought (Olson et al., 2009). Also, human disturbance or hunting may influence grouping dynamics of saigas. Poaching of saigas seems to occur when they form larger groups during November-April when food availability is low (B. Batsaikhan, pers. comm.), but data on actual poaching intensity throughout the year are not available.

As we predicted, typical group size responded negatively to increased predation rate. Animals in larger groups generally benefit from the 'dilution effect', as the individual predation risk per attack is reduced as a function of group size. Thus, forming large groups in saigas is probably a behavioral response to mitigate predation risk. Further, herd formation reduces search efficiency by predators by creating gaps in prey availability across the landscape, analogous to the effects of weak diffusive movements by predators or prey (McCauley, Wilson \& de Roos, 1993; Keeling, Wilson \& Pacala, 2000). Thus, sociality may have reduced the frequency at which predators encounter prey (Cosner et al., 1999; Nachman, 2006). Negative effects of large group size, such as increased competition (i.e. reduced foraging success) and risk of disease transmission, can act against the formation of larger groups, but are outweighed by the advantages when predation risk is high.

There was a positive, but insignificant, relationship observed between typical group size and the density of livestock herders. Although overall density of the saiga population is low (Young et al., 2010), group size may be affected by sympatric livestock herds, given that livestock biomass currently exceeds that of saigas by nearly 50:1 in the study area (J. Berger, unpubl. data). Livestock herder density may not have reflected livestock population densities sufficiently to detect any impacts on saigas; however, we suggest the scale at which saiga and livestock occupy the landscape is too different to influence saiga grouping behavior. In our study area, there is a lack of permanent ground water and local herders rely heavily on hand-drawn wells that are limited in their spatial distribution. The distribution of herders is highly restricted to wells, while saigas move over large areas (Berger et al., 2008). 
Table 2 Model selection results for estimation of factors affecting grouping dynamics of saigas in western Mongolia during 2009-2012. We present results of top 10 ranked models that have AICc weight $>0.002$, although 14 subset models were considered

\begin{tabular}{|c|c|c|c|c|}
\hline Model structure & $\mathrm{AlCc}$ & Delta AICc & AICc weights & Deviance \\
\hline Season + NDVI + predation & 83.961 & 0.000 & 0.562 & 0.761 \\
\hline Season + NDVI & 85.593 & 1.632 & 0.248 & 0.815 \\
\hline Season + NDVI + livestock & 86.701 & 2.740 & 0.143 & 0.797 \\
\hline Predation & 91.735 & 7.774 & 0.041 & 0.379 \\
\hline Season + predation & 92.329 & 8.368 & 0.009 & 0.519 \\
\hline NDVI & 92.654 & 8.693 & 0.007 & 0.329 \\
\hline NDVI + livestock & 93.024 & 9.063 & 0.006 & 0.490 \\
\hline NDVI + predation & 93.050 & 9.089 & 0.006 & 0.489 \\
\hline Predation + livestock & 95.076 & 11.115 & 0.002 & 0.395 \\
\hline Season & 95.185 & 11.224 & 0.002 & 0.172 \\
\hline
\end{tabular}

AICc, corrected AIC; Delta AICc, difference between model AICc and the minimum AICc; AICc weights, model AICc weight; Deviance, proportion of deviance explained by the model.

Table 3 Parameter estimates of the top model explaining changes in monthly typical group size of saigas in western Mongolia, during 2009-2012

\begin{tabular}{lcrcl}
\hline & Estimate & \multicolumn{1}{c}{ SE } & $t$ value & $P$ \\
\hline Intercept & 20.31 & 4.79 & 4.23 & $<0.002$ \\
NDVI & -283.05 & 60.17 & -4.70 & $<0.001$ \\
Predation rate & -4.241 & 1.50 & -3.47 & $<0.001$ \\
Season & 3.69 & 0.91 & 4.06 & $<0.002$ \\
\hline
\end{tabular}

In summary, we found factors involved in explaining changes in saiga group size in western Mongolia could have implications for saiga conservation efforts. Our results suggest saiga form large groups to reduce predation risk and increase reproductive opportunities. Large groups are also easier for humans to find, especially those interested in poaching, and are likely to cause disruptions in saiga grouping behavior.

\section{Acknowledgments}

This research was funded by the Wildlife Conservation Society, World Wide Fund for Nature, Rufford Small Grants Foundation, EDGE Fellowship grant, and Asia Seed Grants Program of Cleveland Metroparks Zoo. We thank Ts. Buyanbat, saiga ranger, for monitoring the marked animals and all of the research assistants who helped during the calving seasons; D. Odonkhuu for his help with the Geographic Information System and Remote Sensing analysis.

\section{References}

Amgalan, L., Buuveibaatar, B. \& Chimeddorj, B. (2008). Current distribution and number of the Mongolian saiga (Saiga tatarica mongolica). J. Inst. Biol. 27, 4-6. (in Mongolian).

Banks, P.B. (2001). Predation-sensitive grouping and habitat use by eastern grey kangaroos: a field experiment. Anim. Behav. 61, 1013-1021.
Bannikov, A.G. (1954). Mammals of the Mongolian People's Republic. Moscow: Nauka Press. (in Russian).

Bekenov, A.B., Grachev, I.A. \& Milner-Gulland, E.J. (1998). The ecology and management of the saiga antelope in Kazakhstan. Mamm. Rev. 28, 1-52.

Berger, J. (1978). Group size, foraging, and antipredator ploys: an analysis of bighorn sheep decisions. Behav. Ecol. Sociobiol. 4, 91-100.

Berger, J. (1988). Social systems, resources, and phylogenetic inertia: an experimental test and its limitations. In Ecology of social behavior: 159-186. Slobodchikoff, C. (Ed.). New York: Academic Press.

Berger, J., Berger, K.M., Bergen, S., Buuveibaatar, B., Fine, A.E., Lkhagvasuren, B., Young, J.K. \& Zahler, P. (2008). Migration bottlenecks, climate, and the conservation of Pleistocene relicts in Central Asia. Open Conserv. Biol. J. 2, 9-10.

Blank, B., Yang, W., Xia, C. \& Xu, W. (2012). Grouping pattern of the goitered gazelle, Gazella subgutturosa (Cetartiodactyla: Bovidae) in Kazakhstan. Mammalia 76, 149-155.

Bon, R., Gonzalez, G., Im, S. \& Badia, J. (1990). Seasonal grouping in female moufflons in relation to food availability. Ethology 86, 224-236.

Borkowski, J. (2000). Influence of the density of a sika deer population on activity, habitat use, and group size. Can. J. Zool. 78, 1369-1374.

Borkowski, J. \& Furubayashi, K. (1998). Seasonal and diel variation in group size among Japanese sika deer in different habitats. J. Zool. (Lond.) 245, 29-34.

Burnham, K.P. \& Anderson, D.R. (2002). Model selection and multi-model inference: a practical information-theoretic approach. 2nd edn. New York: Spring-Verlag.

Buuveibaatar, B. (2011). Factors affecting survival and causespecific mortality of saiga calves (Saiga tatarica mongolica) in Mongolia. MSc thesis, University of Massachusetts Amherst, Massachusetts. 
Buuveibaatar, B., Gunbat, G. \& Fuller, T.K. (2012). Food habits and dietary overlap among livestock and saigas in Mongolia. Saiga News 14, 14-16.

Buuveibaatar, B., Young, J.K., Berger, J., Fine, A.E., Lkhagvasuren, B., Zahler, P. \& Fuller, T.K. (2013). Factors affecting survival and cause-specific mortality of saiga calves in Mongolia. J. Mamm. 94, 127-136.

Buuveibaatar, B., Young, J.K. \& Fine, A.E. (2010). Mongolian saiga in Sharga Nature Reserve: are domestic dogs a threat to saiga? Mong. J. Biol. Sci. 7, 37-43.

Chimeddorj, B., Amgalan, L. \& Buuveibaatar, B. (2009). Current status and distribution of the saiga in Mongolia. Saiga News 8, 1-2.

Clark, E.L. \& Javzansuren, M. (2006). Saiga tatarica. In Mongolian red list of mammals: 64-68. Clark, E.L., Javzansuren, M., Dulamtseren, S., Baillie, J.E.M., Batsaikhan, N., King, S.R.B., Samiya, R. \& Stubbe, M. (Eds). London: Zoological Society of London.

Cosner, C., DeAngelis, D.L., Ault, J.S. \& Olson, D.B. (1999). Effects of spatial grouping on the functional response of predators. Theor. Popul. Biol. 56, 65-75.

Coulson, G. (1993). The influence of population density and habitat on grouping in the western grey kangaroo, Macropus fuliginosus. Wildl. Res. 20, 151-162.

Das, S. \& Chatterjee, S. (2011). Multicollinearity problem root cause, diagnostics and way outs. SSRN eLibrary. (Online DOI: 10.2139/ssrn.1830043)

Dulamceren, S. \& Amgalan, L. (1994). Data on the reproduction of Mongolian saiga antelope (Saiga tatarica mongolica Bannikov 1946). Beitragezur Jagd-und Wildforschung, Bd. 19, 125-127. (in Germany, English abstr.).

Estes, R.D. (1974). Social organization of the African Bovidae. In The behaviour of ungulates and its relation to management: 210-252. Geist, V. \& Walther, F. (Eds). Morges: IUCN.

Festa-Bianchet, M. \& Apollonio, M. (2003). Animal behavior and wildlife conservation. Washington, DC: Island Press.

Gaillard, J.M., Festa-Bianchet, M. \& Yoccoz, N.G. (1998). Population dynamics of large herbivores: variable recruitment with constant adult survival. Trends Ecol. Evol. 13, 58-63.

Ginsberg, J.R. \& Milner-Gulland, E.J. (1994). Sex-biased harvesting and population dynamics in ungulates - implications for conservation and sustainable use. Conserv. Biol. 8, 157-166.

Hamilton, W.D. (1971). Geometry for the selfish herd. $J$. Theor. Biol. 31, 295-311.

IUCN (2011). IUCN red list of threatened species. Version 2011.1. http://www.iucnredlist.org. Downloaded on 07 February 2012.

Jarman, P.J. (1974). The social organisation of antelope in relation to their ecology. Behaviour 48, 215-267.

Keeling, M.J., Wilson, H.B. \& Pacala, S.W. (2000). Reinterpreting space, time lags, and functional responses in ecological models. Science 290, 1758-1761.
Kholodova, M.V., Milner-Gulland, E.J., Easton, A.J., Amgalan, L., Arylov, Y.A., Bekenov, A., Grachev, Y.A., Lushchekina, A.A. \& Ryder, O. (2006). Mitochondrial DNA variation and population structure of the critically endangered saiga antelope Saiga tatarica. Oryx 40, 103107.

Kuhl, A. (2008). The conservation ecology of the saiga antelope, Saiga tatarica. PhD thesis, Imperial College, London.

Li, C., Jiang, Z., Li, L., Li, Z., Fang, H., Li, C. \& Beauchamp, G. (2012). Effects of reproductive status, social rank, sex and group size on vigilance patterns in Przewalski's gazelle. PLoS ONE 7, 32607.

Lkhagvasuren, B., Chimeddorj, B. \& Sanjmyatav, D. (2012). Analyzing the effects of infrastructure on migratory terrestrial mammals in Mongolia. Saiga News 14, 13-14.

Lushchekina, A.A., Dulamtseren, S., Amgalan, L. \& Neronov, V.M. (1999). The status and prospects for conservation of Mongolian saiga, Saiga tatarica mongolica. Oryx 33, 21-30.

McCauley, E., Wilson, W.G. \& de Roos, A.M. (1993). Dynamics of age-structured and spatially structured predator-prey interactions: individual-based models and population-level formulations. Am. Nat. 142, 412-442.

Milner-Gulland, E.J., Bukreeva, O.M., Coulson, T., Lushchekina, A.A., Kholodova, M.V., Bekenov, A. \& Grachev, I.A. (2003). Reproductive collapse of saiga antelope harems. Nature 422, 135.

Nachman, G. (2006). A functional response model of a predator population foraging in a patchy habitat. J. Anim. Ecol. 75, 948-958.

Olson, K.A., Mueller, T., Bolortsetseg, S., Leimgruber, P., Fagan, W.F. \& Fuller, T.K. (2009). A mega-herd of more than 200000 Mongolian gazelles Procapra gutturosa: a consequence of habitat quality. Oryx 43, 149-153.

Payer, D.C. \& Coblentz, B.E. (1997). Seasonal variation in California bighorn ram (Ovis Canadensis californiana). Northwest Sci. 71, 281-288.

R Development Core Team (2008). A language and environment for statistical computing. Vienna: R Foundation for Statistical Computing.

Reiczigel, J., Lang, Z., Rózsa, L. \& Tothmeresz, B. (2008). Measures of sociality: two different views of group size. Anim. Behav. 75, 715-721.

Roberts, G. (1996). Why individual vigilance declines as group size increases. Anim. Behav. 51, 1077-1086.

Singh, N.J., Grachev, I.A., Bekenov, A.B. \& Milner-Gulland, E.J. (2010). Tracking greenery across a latitudinal gradient in central Asia - the migration of the saiga antelope. Divers. Distrib. 16, 663-675.

Sokolov, V.E. (1974). Saiga tatarica. Mamm. Species 38, 1-4.

Thirgood, S.J. (1996). Ecological factors influencing sexual segregation and group size in fallow deer (Dama dama). J. Zool. (Lond.) 239, 783-797.

Walsh, C. \& MacNally, R. (2004). hier.part: Hierarchical Partitioning. $\mathrm{R}$ package version 1.0 . 
White, P.J., Gower, C.N., Davis, T.L., Sheldon, J.W. \& White, J.R. (2012). Group dynamics of Yellowstone pronghorn. J. Mammal. 93, 1129-1138.

Young, J.K., Murray, K.M., Strindberg, S., Buuveibaatar, B. \& Berger, J. (2010). Population estimates of Mongolian saiga: implications for effective monitoring and population recovery. Oryx 44, 285-292.
Yu, F., Price, K.P., Ellis, J., Feddema, J.J. \& Shi, P. (2004). Interannual variations of the grassland boundaries bordering the eastern edges of the Gobi Desert in central Asia. Int. J. Remote Sens. 25, 327-346. 